\title{
MAINGUENEAU, D. DISCURSO LITERÁRIO. TRAD. A. SOBRAL. SÃO PAULO: CONTEXTO, 2006, 329 PÁGS.
}

\author{
Resenbado por: Fernando Antônio Dusi Rocha
}

Discurso literário é a última obra traduzida no Brasil de Dominique Maingueneau, professor de Lingüística na Universidade de Paris XII e respeitado especialista em Análise de Discurso. Sua tradução ficou a cargo de Adail Sobral, doutor em Lingüística Aplicada e Estudos da Linguagem pelo LAEL/PUC-SP.

No prefácio de sua obra, Maingueneau desde logo fixa os contornos de sua mais nova reflexão sobre as relações entre lingüística e literatura: não se trata de um manual voltado para resumir as realizações de uma disciplina estabelecida, pois o terreno que o livro percorre ainda se acha em constituição. De fato, as teorias da enunciação lingüística, as múltiplas correntes da pragmática e da análise de discurso, o desenvolvimento no campo literário dos trabalhos que se reportam a Bakhtin, à retórica, à teoria da recepção, à intertextualidade ou à crítica social, impuseram uma nova concepção do fenômeno da literatura, no qual o dito e o dizer, o texto e o contexto, são inseparáveis. O solo que ainda se encontra em constituição tem uma base bem definida, qual seja, a linguagem como discurso, que permite conceber a literatura não simplesmente como texto, mas como um processo "que permite desestabilizar a distinção entre 'texto' e 'contexto"”, na expressão do próprio Maingueneau (2002).

Daí a advertência prefacial do lingüista: o que está prestes a ruir não é apenas nosso olhar sobre a literatura, "mas o próprio espaço do qual a apreendemos" (p. 8). A metáfora do olhar não é isenta de riscos (nem de desestabilizações), pois criaria a ilusão de vermos um objeto estável, caso aprimorássemos nossos instrumentos de percepção, deixando de enxergar a oscilação na constituição de objetos e nos procedimentos de análise de acordo com o estatuto dos agentes, bem como dos lugares que esses ocupam na circulação dos discursos. Sob a ótica dessa figuração, o discurso literário mostra-se ambíguo. De um lado porque ele reivindica um verdadeiro tipo de discurso, vinculado a um estatuto pragmático. De outro, porque é um rótulo que não designa uma unidade estável, mas permite agrupar um conjunto de fenômenos que fazem parte de épocas e sociedades distantes entre si. É precisamente sob influxo da consciência desse duplo estatuto que Maingueneau propõe seu olhar, tomando a maioria dos seus exemplos da literatura ocidental, sobretudo a francesa, entre os séculos XVI e $\mathrm{XX}$, sem deixar de fazer incursões fora desse corpus de referência. 
O livro está organizado em seis capítulos. No primeiro deles, Maingueneau enuncia as condições do discurso literário, primeiro com a estilística orgânica, depois com a história da filologia, a abordagem marxista, o estruturalismo e a nova crítica, até a emergência do discurso e da instituição discursiva. No segundo capítulo, disserta sobre o discurso literário como discurso constituinte, apontando para as condições das constituências literária e filosófica e para o quadro hermenêutico que garante que um dado texto deve ser interpretado. No terceiro, Maingueneau cuida da paratopia, conceito forjado para indicar um pertencimento impossível da instituição literária, explorando-o nas acepções de paratopia criadora e de embreagem paratópica. No quarto capítulo, o autor trata da posição estéti$c a$, outro conceito novo que diz respeito à vocação enunciativa, abordado sob o prisma da memória intertextual e do investimento de algum gênero (investimento genérico) ou do deslocamento da problemática da língua para a interlíngua.

No quinto capítulo, cuida dos meios e dos gêneros de discurso, já que a própria palavra literatura remete a um dispositivo material de comunicação. Aqui se aborda a questão da tradicional oposição entre o oral e o escrito, bem como da imprensa (a literatura escrita), das novas tecnologias que subvertem a questão da textualidade (o livro eletrônico) e dos gêneros na análise de discurso. No último capítulo, Maingueneau fala da situação de comunicação e da cena de enunciação, apresentando o conceito de cenografia, que é o conjunto de elementos de uma cena de fala que o próprio texto precisa validar mediante sua própria enunciação.

Maingueneau explora com maestria o terreno em constituição da análise de discurso. Mesmo quando se vale de conceitos já estabelecidos (como cena de enunciação, discurso constituinte, gênero de discurso e campo literário), ele é capaz de demonstrar o descentramento do estudo da literatura. De fato, no espaço estético aberto pelo romantismo até os anos 1960, o único objeto de estudo literário era o autor, de maneira direta ou indireta. Diretamente quando se estudava sua vida, indiretamente quando se estudava o contexto de sua criação. Ainda que se tratasse de uma análise estilística, buscava-se uma visão de mundo abandonada pelo estruturalismo, que deslocou o centro de investigação para o texto. Hoje, renunciou-se à busca de um centro, ou pelo menos, se há um centro, é num sentido bem diferente: o próprio dispositivo de comunicação, ou seja, o ato de enunciação.

Dessa forma, quando se apreendem as obras como discursos, faz-se da enunciação o eixo de inteligibilidade do discurso literário. Na verdade, segundo Maingueneau (2002) desloca-se o eixo da seguinte forma 
do texto a um dispositivo de parole onde as condições do dizer atravessam o dito e onde o dito reenvia às suas próprias condições de enunciação ( o estatuto do escritor associado ao seu modo de posicionamento no campo literário, aos papéis ligados aos gêneros, a relação ao destinatário construído através da obra, os suportes materiais e os modos de circulação dos enunciados...).

Em Discurso literário, Maingueneau busca indícios deste descentramento/deslocamento mediante a introdução de alguns conceitos novos, como é o caso da paratopia e da posição estética.

O conceito de paratopia é construído em contraste com a doxa advinda da estética romântica que privilegia a singularidade do criador e minimiza o papel dos destinatários, bem como o caráter institucional do exercício da literatura. $\mathrm{O}$ espaço literário faz, num certo sentido, parte da sociedade, mas a enunciação literária desestabiliza a representação de um lugar, algo dotado de "um dentro" e de "um fora". A existência social da literatura supõe a impossibilidade de ela fechar-se em si mesma e a de confundir-se com a sociedade comum. Mas, paradoxalmente, supõe também a necessidade de jogar com esse meio-termo. Isso obriga os criadores a alimentar-se de lugares, grupos, comportamentos que são tomados num "pertencimento impossível". A literatura, como discurso constituinte, "pode ser comparada a uma rede de lugares na sociedade, mas não pode encerrar-se verdadeiramente em nenhum território" (p. 92). O pertencimento ao campo literário não é, portanto, uma "ausência de todo lugar, mas, como dissemos, uma negociação entre lugar e não-lugar, um pertencimento parasitário que se alimenta de sua inclusão impossível" (idem).

A paratopia, assegura Maingueneau, só existe se integrada a um processo criador. O escritor é alguém que "não tem lugar/uma razão de ser ( nos dois sentidos da locução) e que deve construir o território por meio desta mesma falha" (p. 108). Trata-se de um pertencimento paradoxal: simultaneamente é aquilo que se precisa ficar livre por meio da criação e aquilo que a criação aprofunda. É ela que torna possível a atividade de criação e de enunciação e que desestabiliza a distinção espontânea entre texto e contexto, apontada pelo próprio autor.

Não se pode deixar de registrar que o conceito de paratopia guarda uma persuasiva similitude com o conceito bakhtiniano de exotopia, que é o situarse em um lugar exterior. A criação estética expressa a diferença e a tensão entre dois olhares, entre dois pontos de vista. Tomando o exemplo do retrato, em pintura, falamos do olhar do(a) retratado(a) e do olhar do(a) retratista ou artista. $\mathrm{O}$ (a) retratista tenta entender o ponto de vista do(a) retratado(a), retra- 
tando o que vê como o outro vê, o que olha como o outro olha. Nas palavras de Amorim (2006:96): "De seu lugar exterior, situa o retratado num dado ambiente, que é aquilo que cerca o retratado, e em relação ao qual é situado pelo artista".

Exotopicamente falando, a ambiência é uma delimitação dada pelo(a) artista, uma espécie de moldura que enquadra o(a) artista. Paratopicamente falando, a moldura não parece ser nem a origem nem a causa da enunciação da obra literária, mas um entrelugar que possibilita a construção de seu próprio desenvolvimento, ao mesmo tempo em que permite a configuração e simultaneamente nega a existência de um universo paralelo e autônomo à obra. Entre o 'eu' criador profundo e um 'eu' superficial - diz Maingueneau - ou entre o sujeito do texto e o sujeito biográfico, "implica dar conta dos entrelaçamentos de níveis, de retroações, dos ajustes instáveis, das identidades que não se podem fechar" (p.119). Pode-se, portanto, cogitar muito mais do que uma similitude entre o conceito fundante de Bakhtin e o concebido por Maingueneau. Na verdade, chegamos a pensar numa transitividade na relação exotopia/paratopia, de tal forma que essa última valida-se conceitualmente a partir da primeira.

$\mathrm{Na}$ busca das evidências daquele descentramento, vale conferir os exemplos dados pelo autor, a fim de atestar até que ponto os entrelaçamentos alcançados pela paratopia permitem que as condições do dizer ultrapassem o dito e que o dito remeta-se às próprias condições da enunciação.

O outro conceito a ser abordado é o de posição estética. Como todo discurso constituinte, o discurso literário mantém relação com a memória, com um certo arquivo literário impregnado, implícita ou explicitamente, por valores legados por uma tradição. Para posicionar-se, o criador, diz Maingueneau, deve definir trajetórias próprias no intertexto. A obra forma unidade com a gestão de sua identidade no intertexto, estruturando-se por meio de tensões que a tornam possível. Há um estreito relacionamento entre posição e memória intertextual.

Contudo, as obras literárias alimentam-se não só de outras obras como também de relações com enunciados que nada têm a ver com literatura. Na expressão de Maingueneau: "toda obra se divide a priori entre a imersão no corpus então reconhecido como literário e a receptividade a uma multiplicidade de outras práticas verbais" (p. 166). A relação com o não-literário é redefinida incessantemente. A delimitação daquilo que pode ou não alimentar a literatura, mas também advir da literatura, "se confunde com cada posicionamento e cada gênero no interior de um certo regime de produção discursiva" (idem). Daí por que o conceito de posição é profundamente esclarecedor para ver de 
que forma o discurso literário situa-se no interior de um conjunto interdiscursivo; para surpreendê-lo em suas aproximações em seus contatos e liames com outras áreas discursivas; para ver como se relacionam, interagem; como certos procedimentos migram de uma área para outra e para descobrir-lhes regras de formação análogas e de diferenças.

Muito embora Maingueneau prestigie, em cada conjuntura, o mosaico de práticas não-literárias que mantêm com a literatura uma relação privilegiada, o autor não chega a dar conta das conexões do discurso literário com domínios não-discursivos. No entanto, suas conclusões não se limitam à textualidade, mesmo porque, como assevera ao final da obra, a história mostra claramente que o estudo do discurso literário não deve ser exclusivamente literário. A intervenção de problemáticas da análise de discurso no domínio das "humanidades tradicionais" implica uma "superação de fronteiras disciplinares que põe em questão, para além das atitudes, um modo de definir a identidade do mundo acadêmico" (p. 324).

O terreno em constituição na análise de discurso é inegavelmente $p a$ ratópico: o dizer ultrapassando o dito, um universo que se constrói e que, de forma paradoxal, nega-se no limiar do texto e do contexto.

\section{ReferênCIAS Bibliográficas}

Amorim, M. Cronotopo e exotopia. In: Bakhtin. Outros conceitos-chave. Brait, B. (Org). São Paulo: Contexto, 2006, p. 96.

Maingueneau, D. Linguistique et littérature. Le tournant discursif. In : Vox Poetica, 05/06/2002, http://www.vox-poetica.org/t/maingueneau.html 